\title{
UNA MIRADA A «ALGO MÁS ACERCA DE LA RELACIÓN ENTRE DERECHO Y MORAL» (1992) DE ERNESTO GARZÓN VALDÉS
}

\author{
Victoria Roca \\ Universidad de Alicante
}

RESUMEN. Las tesis sostenidas por Garzón Valdés en el trabajo aquí analizado permiten poner de manifiesto cómo una adecuada comprensión del Derecho como práctica normativa que se pretende justificativa de acciones que afectan a terceros nos lleva a vincular el Derecho con la Moral sin por ello 1) abandonar las filas del positivismo ni 2) caer en un discurso acrítico en relación con el Derecho. Esas tesis además pueden verse como una invitación a una reflexión acerca del fundamento último y de las claves que permiten entender cabalmente la denominada pretensión de corrección del Derecho.

Palabras clave: Ernesto Garzón Valdés, Derecho y moral, regla de reconocimiento, positivismo jurídico, pretensión de corrección.

ABSTRACT. Garzón Valdés argues in «Algo más acerca de las relaciones entre Derecho y Moral» for the thesis on the necessary justificatory and conceptual connection between Law and Morality. $\mathrm{He}$ states that an adequate understanding of Law as a normative practice aiming at justifying actions and the use of force is only possible when maintaining that referred thesis. Nonetheless this does not lead us neither to abandon a positivistic approach to the Law nor to fall into an uncritical discourse about it. Further, those ideas stimulate us to consider the grounds and the clues to a correct reconstruction of the correction claim erected by the Law.

Keywords: Ernesto Garzón Valdés, Law and Morality, recognition rule, legal positivism, correction claim. 
o es difícil llegar al acuerdo de que las relaciones entre el Derecho y la Moral han sido y siguen siendo núcleo o problema central de la Filosofía del Derecho. Es, sin embargo, más difícil llegar a acordar cuál sea la naturaleza de esas relaciones, en qué dimensión se dan, qué implicaciones tienen con otros problemas de la iusfilosofía y de la teoría del Derecho, etc.

Son dos las tesis defendidas por Ernesto GARZÓN en su artículo del año 1992 «Algo más acerca de la relación entre el Derecho y la Moral», con las cuales propone también su contribución a este espinoso debate:

1. Entre los Derechos existentes y la Moral (en su doble versión de moral positiva y de moral crítica o ética) se da una conexión conceptual necesaria. Al menos los legisladores y los funcionarios tienen que adherirse a la regla de reconocimiento por razones morales (GARZÓN VALDÉS, 1992: 324).

2. La tesis anterior es relevante para entender cómo es y cómo funciona en realidad el Derecho, pero su aceptación no implica dotar de un halo de moralidad —-blindada frente a la crítica- al Derecho positivo (GARZÓN VALDÉS, 1992: 333 ).

Ernesto GARZÓN suscribe la tesis de la unidad del razonamiento práctico. Por decirlo con las palabras clásicas de KANT en la Fundamentación de la metafísica de las costumbres (1785): «Todos los deberes, simplemente porque son deberes pertenecen a la Ética; pero su legislación no está contenida para todos en la Ética, sino fuera de la misma para muchos de ellos». En definitiva, para los autores que, como GARZÓN VALDÉs, suscriben esta tesis tendremos distintas variedades de obligaciones siempre morales distinguibles en razón de la diversidad de prácticas o instituciones que cabe tomar en cuenta como razones auxiliares en los razonamientos prácticos complejos ${ }^{1}$.

¿Cuáles son los hitos de la argumentación que lleva a Ernesto GARZÓN a defender la tesis de la conexión conceptual del Derecho con la Moral?

Siguiendo la terminología hartiana, aunque aquí no sus tesis sustantivas, el profesor GARZÓN parte de que los participantes en un sistema jurídico pueden incluir las reglas jurídicas en sus razonamientos prácticos de dos formas distintas:

a) Bien asumiendo un punto de vista interno. Entonces hablaríamos de aceptación de la regla.

b) Bien asumiendo un punto de vista externo o prudencial. Hablamos entonces de obediencia (GARZÓN VALDÉs, 1992: 320).

A la pregunta que se le dirige a la parte oficial (jueces y legisladores centralmente) acerca de por qué considera que debe obedecerse lo que establece la Constitución, la única respuesta que puede considerarse correcta —nos dice GARZÓN VALDÉS— es aquella que pasa por apelar a razones extrajurídicas y últimas: en definitiva, a razones morales (GARZÓN VALDÉS, 1992: 321).

\footnotetext{
${ }^{1}$ BAYÓN, 1991: 447.
} 
Vistas las cosas desde el punto de vista interno (el del aceptante), el Derecho, pues, no aparece meramente conectado con la moral, sino con la Etica o moral crítica: quienes aceptan o suscriben internamente las normas lo hacen porque consideran que ellas son las verdaderamente correctas. La expresión del punto de vista interno es siempre también una proposición moral interna. Hablamos aquí de «creencia en la legitimidad» (GARZÓN VALDÉS, 1992: 321).

Se abre con esto un bloque de preguntas de interés: ¿Es posible la formación de un sistema jurídico sin la existencia real de aceptantes en la clase oficial, esto es, basta para ello con la creencia (falsa) generalizada entre la clase oficial de que hay aceptantes entre sus miembros? ¿Es viable la estabilidad de un sistema desde esa apariencia generalizada en la clase oficial? ¿Son empíricamente posibles Irrlandia (todos están en un error acerca de las creencias verdaderas de los otros), Delirandia (todos están en un error acerca de las creencias verdaderas de los otros y además ninguno de los ciudadanos se atreve a sacar a la parte oficial de su error a pesar de que ello los podría liberar de un régimen que ellos rechazan) o Apatilandia (la parte oficial no padece los efectos de la creencia errónea, sino que no tiene ninguna creencia acerca del valor de las reglas básicas del sistema: simplemente las cumple por hábito, tradición o aburrimiento y, además, los «apatilandios» no se han planteado nunca en ninguno de sus estratos sociales la pregunta acerca de por qué actúan como actúan? (GARZÓN VALDÉS, 1992: 322).

Ernesto GARZÓN considera que tales sistemas serían estructuralmente muy inestables, pero afirma que, aunque improbable, su existencia sería posible. Quizá valdría la pena suscitar aquí con Gregory KAVKA ${ }^{2}$ y con Juan Carlos BAYÓN la pregunta acerca de si es precisa siquiera la creencia (errónea) generalizada de que los demás aceptan realmente la regla o si acaso no bastaría para la existencia de una regla social incluso sólo con la creencia (errónea) de que nadie sabe que todos sabemos que los demás no aceptan la regla (BAYÓN, 1991: 457-458).

$\mathrm{Al}$ margen de estas consideraciones, lo que sí es común a todas estas posiciones es que la categoría «conducta de aceptación» se constituye en el eje central para explicar la noción de regla y, con ella, la noción de Derecho.

En opinión de Ernesto GARZÓN es preciso subrayar que el sistema jurídico no puede existir sin la pretensión de corrección moral de su regla de reconocimiento (lo que ALEXY denomina también la pretensión de justicia) ${ }^{3}$. Es más, nos dice el profesor GARZÓN, si la parte oficial no puede pretender legitimidad por ella misma, no tenemos base sobre la cual podamos acordarle una legitimidad ni siquiera de facto (GARZÓN VALDÉs, 1992: 330). Esta tesis me parece sin embargo susceptible de controversia. En efecto, bien podría avanzarse que la legitimidad en el mundo de la razón práctica no implica sólo, tal y como se presume en el texto de GARZÓN, la pretensión de legitimidad y su correspondencia con una serie de valores o principios éticos correctos, sino también junto a ello, y como condición necesaria, la circunstancia de que de hecho la norma o la autoridad sea considerada como legítima por un grupo.

Volvamos al hilo central del texto de GARZÓN VALDÉs: si bien un juez puede pronunciar una sentencia conforme a la ley vigente aunque no suscriba internamente el

\footnotetext{
2 KavKa, 1983.

3 Alexy, 1997: 41-46.
} 
contenido de la misma, el problema radica en saber si esta actitud puede conceptualmente ser generalizada. La respuesta de Ernesto GARZÓN es negativa. Para quienes adoptan el punto de vista interno legitimación coincide con legitimidad (entendida esta última como coincidencia de las normas del sistema con los principios de la ética) ${ }^{4}$. De la misma forma que sería contradictorio afirmar «creo que la pared es blanca y no es así», o el archicitado «el gato está sobre la alfombra pero yo no lo creo» lo sería también «creo en la legitimidad de mi sistema pero es ilegítimo». Además, lo que resulta chocante en la opinión de RADBRUCH cuando sostiene que «despreciamos al párroco que predica en contra de sus convicciones, pero honramos al juez que no se deja engañar en su fidelidad a la ley por una sensibilidad jurídica contraria a ella» ${ }^{5}$, es que hay una contradicción entre las proposiciones que expresan el punto de vista interno de ese juez y sus proposiciones morales internas (GARZÓN VALDÉS, 1991: 332). Vistas así las cosas, la actitud de desprecio frente a este juez podría estar plenamente justificada. Aquí, en efecto, estaríamos cuestionando no sólo la integridad moral de este juez, sino su coherencia pragmática. Con esto, GARZÓN se estaría apartando de opiniones tales como la expresada por MAYES del siguiente modo: «No hay nada inconsistente en la idea de que uno o incluso todos los jueces de una sociedad impongan el Derecho meramente para evitarse los inconvenientes que personalmente habrían de soportar si hicieran lo contrario. Criticar a los infractores del Derecho es parte de su trabajo ¿por qué habríamos de propugnar como condición necesaria que sus críticas sean sinceras? (MAYES, 1989: 239). Pues bien, dejando a un lado si es o no es lógicamente necesaria la aceptación generalizada por parte de los jueces para hablar de la existencia de una regla social, tiene en mi opinión razón el profesor GARZÓN cuando dice que es posible formular un juicio desaprobatorio contra el juez que no emita sus juicios críticos de forma sincera. En este punto, el artículo del profesor argentino nos permite abrir de nuevo un bloque de preguntas de gran interés: el relativo, precisamente, a los problemas de contradicción pragmática o al menos aparentes quebrantos de la consistencia pragmática que presentarían formulaciones tales como las que a modo de ejemplo se me ocurren:

1. Esta ley es ilegítima pero yo no lo creo.

2. Debo resolver conforme a este Derecho al que considero injusto.

3. Debo resolver conforme a este Derecho, y tal deber lo considero injusto.

4. Debo resolver conforme a esta ley, a la que considero injusta.

5. Debo resolver conforme a esta ley, y tal deber lo considero injusto.

6. Debo condenar a este sujeto, pero creo que es inocente.

7. Debo absolver a este sujeto, pero creo que es culpable.

En definitiva, la lectura de este punto del artículo de Ernesto GARZÓN invita a profundizar en los fundamentos de la pretensión de corrección y a desentrañar los hilos que conducen a una comprensión adecuada del nexo entre corrección jurídica y corrección moral.

Por lo que se refiere al punto de vista del observador externo, y para concluir con la tesis de la conexión conceptual entre Derecho y Moral, nos dice GARZÓN VALDÉS que es obvio que las proposiciones morales internas de un tal observador pueden no

\footnotetext{
${ }^{4}$ GARZÓn VAldÉs, 1991: 321, 327-328.

5 RADBRUCH, 1932: 83.
} 
coincidir con las de quienes aceptan e imponen el sistema objeto de su consideración. De aquí no se sigue sin más que el observador deba necesariamente negar el carácter de jurídico al sistema que considera injusto. De la negación de la tesis de la neutralidad no se sigue la imposibilidad de formular juicios críticos que califiquen a un sistema jurídico como inmoral (GARZÓN VALDÉs, 1991: 328). Con esto, GARZÓN VALDÉS, seguiría manteniéndose dentro de las filas del positivismo jurídico. Hablaríamos en un sentido «entrecomillado»o «indirecto» — dejando aquí al margen los problemas que suscitan este tipo de enunciados- de lo jurídicamente «debido».

\section{II}

En cuanto al segundo problema tratado en este artículo: bajo la postura de quienes como HART o KELSEN sostienen que la tesis de la conexión conceptual del Derecho con la Moral es peligrosa en virtud de las consecuencias prácticas que de ella derivan, subyace - nos dice GARZÓN - la creencia de que el rechazo de la tesis de la separación destruye, o al menos reduce, la capacidad crítica de los ciudadanos: «el efecto real de la identificación terminológica de Derecho y justicia comporta una justificación ilícita de cualquier Derecho positivo» (KELSEN) o «es importante que las personas conserven el sentido de que la certificación de que algo es jurídicamente válido no es concluyente con respecto a la cuestión de la obediencia» (HART). Se supone con ello una vinculación entre la obligación impuesta por la parte oficial, de acuerdo con sus creencias morales, y la creencia en el deber moral de obediencia de estos mandatos por parte de los ciudadanos (GARZÓN VALDÉs, 1991: 330-331).

Traeré aquí algunas ideas ya bien conocidas pero muy controvertidas a partir de esta última reflexión de GARZÓN. El sujeto participante puede ver razones jurídicas (razones morales que se entretejen con razones auxiliares emanadas de una determinada práctica jurídica) y al mismo tiempo conservar una suerte de distanciamiento crítico respecto de las mismas de forma que la conclusión de su razonamiento práctico le lleve a otorgar un mayor peso ( $\mathrm{y}$ bajo su responsabilidad) a otras razones morales diferentes de aquellas que se articulan en torno a la práctica en cuestión y que se constituían en razones para su observancia. En definitiva, si bien el Derecho pretende constituirse en una razón excluyente y articular así un deber de carácter concluyente, la práctica moral en la que está a su vez inmerso puede llevarnos a arrojar una conclusión distinta. Es decir, el Derecho positivo, o una determinada norma jurídica, puede verse derrotado. En este sentido, suscribir la tesis de la conexión entre el Derecho y la Moral no implica sostener que existe una obligación moral de obedecer al Derecho incluso cuando éste pugne contra nuestra conciencia (aunque eso sí, bajo nuestra responsabilidad), ni implica tampoco reconstruir a los ciudadanos como «ciegos morales» ni contribuye necesariamente y por sí sola a generar una opinión de obediencia acrítica al Derecho. En mi opinión cabe decir que más bien debemos confiar en que lo que genera la conciencia de que la única forma legítima de ejercicio de la fuerza pasa por su justificación moral última es la opinión generalizada — por concluir con unas palabras de Ernesto GARZÓN tomadas de POSTEMA ${ }^{6}$ - de que «hay un sentido directo en el cual la fuerza coactiva ins-

\footnotetext{
${ }^{6}$ Postema, 1987: 93.
} 
titucionalizada no puede ser considerada como Derecho que justifique nuestras acciones» (GARZÓN VALDÉS, 1991: 325) y ese sentido, podemos explicitar, alude a la carencia de normatividad — de fuerza justificativa — en los términos antes establecidos.

\section{BIBLIOGRAFÍA}

BAYÓN, J. C., 1991: La normatividad del Derecho: deber jurídico y razones para la acción, Madrid: Centro de Estudios Constitucionales.

GARZÓN VALDÉS, E., 1991: «Algo más acerca de la relación entre Derecho y Moral», Derecho, Ética y Politica, Madrid: Centro de Estudios Constitucionales, pp. 317-335.

Hart, H. L. A., 1994: The Concept of Law, 2. ${ }^{a}$ ed. a cargo de P. A. Bulloch y J. RaZ, Oxford: Clarendon Press.

KavkA, G. S., 1983: «Rule by Fear», Nô̂s, 17: pp. 601-620.

Kelsen, H., 1948: «Law, State and Justice in the Pure Theory of Law», Yale Law Journal, 57/3: pp. 377-390.

MAYES, G. R., 1989: «The Internal Aspect of Law: rethinking Hart's Contribution to Legal Positivism», Social Theory and Practice, 15: pp. 231-255.

Postema, G. J., 1987: «The Normativity of Law», R. GAVISON (ed.), Issues in contemporary Legal Philosopby. The Influence of H. L. A. Hart, Oxford: Clarendon Press, pp. 81-104.

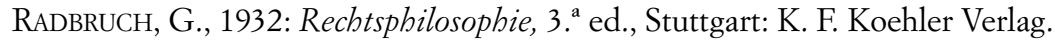

